\title{
DISCURSO SOBRE TRADUÇÃO: ASPECTOS DA CONFIGURAÇÃO IDENTITÁRIA DO TRADUTOR
}

\begin{abstract}
Maria José R. Faria Coracini*
RESUMO: Inserido no bojo de uma pesquisa que se preocupa com a configuração identitária dos sujeitos da linguagem, este texto pretende trazer reflexões sobre a figura do tradutor, a partir da análise de artigos publicados, no Brasil, em periódicos especializados. Assumindo "identidade" como resultante da formação imaginária (no sentido lacaniano), sempre a partir do outro, foi possível concluir que o tradutor é um sujeito heterogeneamente constituído. Uma constituição que se dá por representações múltiplas e conflitantes, provenientes, ao mesmo tempo, de suas experiências como profissional e das representações. Aliás, experiências e representações que teóricos da tradução emitem ou deixam escapar pelos interstícios de seu discurso a seu respeito e a respeito de sua tarefa e que, por serem reconhecidos e legitimados, internalizam de forma mais ou menos consciente. Encontram-se, pois, entre a ânsia de fidelidade e a impossibilidade de ser fiel, entre a busca das intenções do autor e a impossibilidade desse encontro, entre o consciente e o inconsciente, entre a necessidade e a impossibilidade da tradução, entre a reprodução e a criação...
\end{abstract}

UNITERMOS: identidade do tradutor; subjetividade; discurso.

RESUME: Faisant partie d'une recherche centrée sur la configuration identitaire des sujets du langage, ce texte veut

* Universidade Estadual de Campinas, Instituto de Estudos da Linguagem, Departamento de Lingüística Aplicada.

TradTerm, 11, 2005, p. 29-51 
apporter des reflexions sur le traducteur, à partir de l'analyse d'articles publiés, au Brésil, dans des revues spécialisées, consacrées à la traduction. "Prenant identité" comme le résultat de la formation imaginaire lau sens lacanien du terme), toujours à partir de l'autre, on a pu conclure que le traducteur est un sujet hétérogène, constitué par des représentations multiples et en conflit, provenant, en même temps, de ses expériences en tant que professionnel et des représentations que des théoriciens de la traduction expriment ou laissent échapper, par les interstices de leur discours, sur lui et sa tâche et que, étant reconnus et légitimés, il internalise de façon plus ou moins consciente. Le traducteur se trouve, donc, entre le désir de fidélité et l'impossibilité d'être fidèle, entre la poursuite des intentions de l'auteur du texte de base et l'impossibilité de les trouver, entre la nécessité et l'impossibilité de traduire, entre la reproduction et la création...

MOTS-CLES: identité du traducteur ; subjectivité ; discours.

No bojo de uma pesquisa que se preocupa com a configuração identitária dos sujeitos da linguagem, ${ }^{1}$ este texto pretende trazer reflexões sobre a figura do tradutor, a partir da análise de artigos publicados em periódicos especializados dedicados à tradução. Dentre esses, destaquem-se: TradTerm (de 1992 a 2001), Cadernos de Literatura em Tradução $\left(\mathrm{n}^{\circ} 1\right)$ e Trabalhos em Lingüística Aplicada ( $\left.{ }^{\circ} 19\right)$, além de prefácios de obras traduzidas e de algumas coletâneas de textos sobre tradução. Observou-se, nos artigos que serviram de corpus, as imagens de tradução e de tradutor que veiculam, ainda que de forma subjacente, textos produzidos tanto por teóricos da tradução quanto por professores e tradutores que vivenciam, na prática, a tarefa de traduzir de uma língua para outra. Não estaremos, aqui, portanto, trabalhando com a idéia de tradução enquanto atividade que todo e

1 Trata-se do Projeto Integrado CNPq sobre Interdiscurso e Identidade, sob minha coordenação, que recebe, também, auxílio da FAPESP.

TRadTERM, 11, 2005, p. 29-51 
qualquer leitor efetua na sua tarefa de interpretar. Tampouco com o que se denomina "tradução intralingual" (entre variantes de uma mesma língua). Tratamos da "tradução interlingual", a fim de entendermos como se vêem e são vistos os tradutores, já que, conforme apontamos no início, objetivamos estudar a configuração identitária do sujeito tradutor.

Partimos, então, do pressuposto de que o que se diz sobre o outro é constituído pelas auto-representações (ou imagens) desse outro, ao mesmo tempo em que colabora para reforçar ou modificar essas representações. Assim, as representações que têm especialistas ou teóricos da tradução sobre o tradutor e sua tarefa tradutória são constituídas pelas auto-representações do profissional. Ao mesmo tempo constituem um discurso que atravessa, de alguma maneira, o imaginário do profissional da tradução, interferindo na sua configuração identitária. Depois de breves considerações sobre noções como identidade e sujeito, passaremos a comentar resultados da análise de textos especializados extraídos de revistas da área de tradução: num primeiro momento, apresentaremos os principais resultados do estudo sobre as representações dos teóricos da tradução e, num segundo, dos tradutores e professores de tradução.

\section{Considerações preliminares}

Como se sabe, nos últimos anos tem havido um interesse crescente por questões que dizem respeito à identidade: debates, congressos, movimentos falam, discutem, propõem soluções para situações limítrofes, em que povos, nações, grupos, indivíduos se sentem confusos com relação à sua própria definição. Alguns afirmam que estamos vivendo um periodo que se caracteriza pela crise de identidade ou, melhor dizendo, pelo sentimento de perda de identidade - individual, social, nacional provocado, dentre outras causas, pela ideologia da globalização. Esta pretende, embora o camufle em discurso, à centralização e à homogeneização, se não de todos e de tudo, ao menos daqueles ou dos setores cujas características atrapalham ou dificultam, de alguma maneira, o desenvolvimento da economia dos 
países industrializados. Por exemplo, não interessa a esses países acabarem com o que há de exótico em certas culturas desde que essas características não impeçam o seu crescimento econômico; interessa-lhes, sim, manter certas características culturais distintivas que permitam a manutenção e conseqüente adequação de um mercado diferenciado. Ainda a título de exemplo, lembremos que a boneca Barbie se veste e traz consigo objetos da cultura da criança que o fabricante ou o mercado pretende atingir ou transformar em consumidora. Ora, suspeitando da manipulação (para não dizer da tapeação) que estão sofrendo, grupos de intelectuais, associações de toda sorte espalhadas no mundo todo, e várias nações - estimuladas por outros interesses e motivações - vêm promovendo verdadeiros movimentos de mobilização em defesa dos grupos minoritários que se vêem ameaçados de extinção, como os indigenas nos países do Novo Mundo e, no caso de nações, os iraquianos e afegãos, transformados em terroristas pelos americanos conforme recentes acontecimentos.

A esse respeito, Mercer (1990: 04) lembra, com muita propriedade, que "a identidade somente se torna uma questão quando está em crise, quando algo que se supõe fixo, coerente e estável é deslocado pela experiência da dúvida e da incerteza". Assim, numa época em que se questionam as verdades preestabelecidas, os conhecimentos fixos e estáveis, as crenças definitivas que assegura(va)m a existência de um centro - religioso, filosófico ou cultural - todos sem exceção, ameaçados pela hibridação racial e social provocada pela constante migração de uns para o país de outros, vacilam num mundo de fronteiras instáveis, fluidas, descontínuas e porosas, inclusive geograficamente, pois se abrem para cidadãos de outros países (a exemplo da União Européia), deixando reinar a insegurança, a incerteza e a dúvida... Segundo Bauman (2001: 14),

(...) estamos passando de uma era de "grupos de referência" predeterminados a uma outra de "comparação universal", em que o destino dos trabalhos de autoconstrução individual está endêmica e incuravelmente subdeterminado, não está dado de antemão, e tende a sofrer numero- 
sas e profundas mudanças antes que esses trabalhos alcancem seu único fim genuíno: o fim da vida do indivíduo.

Apesar disso, ou justamente por isso, sociedades inteiras insistem em construir verdades (pensemos, por exemplo, nos americanos, nos israelenses e em todos aqueles que desejam e não medem esforços para que suas verdades sejam reconhecidas e legitimadas, mesmo que em conseqüência da violência e da imposição). Insistem em propor categorias, em construir estereótipos reforçados pela mídia, em buscar o absoluto, que dê estabilidade e segurança ainda que ilusórias, ainda que passageiras. Convivem, assim, múltiplos padrões e configurações de vida, de crenças, de orientações filosóficas, mesclando-se, chocando-se entre si, contradizendo-se nas inúmeras individualidades, que são, cada vez mais, responsabilizadas pelos sucessos e pelos fracassos. Resultado do que Bauman (op.cit.: 14) denomina "liquefação dos padrões de dependência e interação", que, "como todos os fluidos, não mantêm a forma por muito tempo".

É nesse contexto, onde reinam as contradições e os conflitos entre o desejo da completude e da totalidade e a contingência do inefável e do incerto, que inserimos nossa pesquisa. É nesse e por causa desse contexto que, ao pensar na identidade do tradutor, fizemos a seguinte pergunta: o que significa ser tradutor? Mas, ao tentar responder essa pergunta, outras surgiram, inevitavelmente, dentre as quais: o que significa traduzir? qual a relação entre a obra original e a obra traduzida? que concepção(ões) de linguagem subjaz(em) ao ato tradutório? Este artigo constitui uma tentativa de trazer algumas reflexões em torno dessas perguntas, com base em outros textos que constituem parte do discurso sobre e do tradutor e sua tarefa.

Voltemo-nos, mais um pouco, para o contexto ao qual estávamos nos referindo, para pensarmos a questão da identidade e, conseqüentemente, a questão do sujeito. Da perspectiva dos estudos sociais, a identidade social e individual pode ser definida como um rol de características que, ao mesmo tempo em que identificam um indivíduo a outros semelhantes (por isso formam um grupo), distinguem-no dos indivíduos do mesmo grupo assim 
como distinguem os grupos entre si. Embora essas características distintivas se modifiquem sob a ação do tempo e do espaço, elas são consideradas suficientemente estáveis para permitirem que os grupos sejam classificados e nomeados cientificamente, até, é claro, que outra classificação mais adequada se imponha. Importa observar que, nesse caso, arrolam-se características observáveis a partir do exterior, do cientista ou do observador. Essas características podem ser assumidas, como afirma Backes (2000: 71), pelas sociedades e pelos indivíduos que a ela pertencem, construindo estereótipos reducionistas, como por exemplo, "o brasileiro é bom de bola" ou "o brasileiro tem o samba nos pés".

Da perspectiva da psicanálise, entretanto, a identidade se resume ao que o sujeito é capaz de dizer (narrar) sobre si, ou seja, sobre o ego (eu), construído necessariamente a partir da relação com o outro - pai, mãe, grupo social... - que o definem e que ele internaliza como sendo ele próprio, no desejo de corresponder ao que o outro deseja dele: afinal, o desejo do sujeito é ser o desejo do outro, é ser amado pelo outro e, para isso, não mede esforços no sentido de ser como o outro deseja que ele seja. É o que parece acontecer com o tradutor, que constrói sua identidade a partir dos vários discursos sobre ele, dos discursos sobre sua(s) tradução(ões) e sobre a tarefa do profissional da tradução, das imagens ou representações que outros - teóricos sobretudo, mas também outros tradutores - deixam escapar pela linguagem.

Isso explica a questão dos modismos e a forte adesão a esta ou àquela maneira de se comportar, de se relacionar. A identidade se constrói no imaginário, nas identificações imaginárias, que podem ou não se transformar em simbólicas, constituindo o Outro do inconsciente, os valores que, sem saber, orientam o individuo, suas escolhas, seu rumo. Assim, identidade e imagem (ou representação) estão sempre associadas a uma narrativa, pois, "a imagem passa por alguém que a produz e a reconhece", como afirma Backes (2000: 70). Essa mesma autora esclarece que "a imagem /.../ adquire um estatuto geral e pode tornar-se a ilusão [que] um grupo crê constituir-se numa identidade" (ibid.: 71). Esse conjunto de imagens adquirem o contorno 
de uma identidade, a qual, segundo a psicanálise, pode ser definida como um "sentimento" (Berry, 1991: 14), por seu caráter totalizante, "insistente e pregnante", imagens essas que são capazes de congelar um sentido (por exemplo, o brasileiro é bom de bola) e lhe conferir o estatuto de verdade.

Como, no encontro com o outro, o reforço de certos traços é inevitável, traços que, de certa forma, nos agradam porque "o eu se sente amparado na imagem do semelhante" (ibid.: 72), provocando, portanto, identificações, o indivíduo acaba assumindo essas imagens como se elas definissem o próprio eu ou o eu de um dado grupo social ou profissional, ou melhor, como se proporcionassem "o encontro com o eu, um reconhecimento". Segundo Backes, Freud afirma que se trata da realização alucinatória do desejo pela imagem que vem a substituir o objeto; desejo do outro que supostamente viria completá-lo e que supostamente seria assim completado; desejo de totalidade, de origem, que se manifesta, no caso em questão, pelo desejo de autoria: ser tradutor é também ser autor; é completar o texto do outro - que se admira e deseja - com seu próprio texto; é ver-se completado, ainda que por um momento...

Num mundo individualizado, em que os valores mudam a cada momento orientados pela economia e pelo marketing, os quais, por sua vez, fazem da aparência o seu lema - e que a mídia e as novas tecnologias reforçam - o sujeito do desejo, o sujeito barrado, o sujeito da falta convive, quando não é por ele atravessado, com um outro tipo de sujeito em emergência nas sociedades ocidentais, capitalistas e neoliberais. Trata-se do sujeito do imaginário ou sujeito das pulsões, que acredita tudo poder, porque crê tudo poder comprar, porque não conhece a falta, o impossivel, o inefável; é sobretudo a falta do objeto a consumir que justifica seus esforços. É o que explica, segundo Melman (2002), a existência de sujeitos que se pautam apenas pelas aparências e que não conseguem expressar com palavras o que sentem: dizem que são felizes porque têm marido, filhos, casa, carro de último tipo ou que ficarão felizes quando possuírem pessoas, objetos... É o sujeito que quer, mas não deseja; é o sujeito que tem, mas não é (ou pelo menos não sabe que é); é o sujeito do consciente, da aparência, que se deixa levar pelo eu 
ideal, pela moda que dita e orienta suas escolhas, seu comportamento; é o sujeito que serve muito bem à sociedade de consumo que tem como único objetivo transformar o mundo, todos os indivíduos, em consumidores - potenciais ou reais. Tomamos, portanto, identidade como uma construção imaginária ou uma soma de construções imaginárias (Backes, 2000: 33), sempre a partir do outro, do discurso-outro.

Não vamos nos estender na questão do sujeito em transformação, mas tudo isso complexifica a subjetividade e torna a identidade fluida, imprecisa, fugaz, sempre em movimento e em constante transformação, deixando o indivíduo solitário (no meio da multidão), desamparado e, por isso mesmo, suscetível a freqüentes crises de depressão (que não sabe - ou não pode? verbalizar). Não restam dúvidas de que o tradutor que, evidentemente, pertence a esse mundo, sofre suas conseqüências, como veremos nos itens que se seguem.

\section{O que dizem teóricos da tradução}

Nos periódicos analisados, duas são as principais visões do que seja 'ser tradutor' e do que seja 'traduzir', em torno das quais giram variantes que não serão aqui trazidas a não ser quando forem elucidativas para a questão que nos interessa. Tais visões, quando não estão explicitadas nos textos, encontram-se subjacentes a dois diferentes procedimentos utilizados pelos teóricos para discutirem aspectos da tradução que consideram relevantes para seus objetivos. Esses procedimentos podem ser assim sintetizados:

1) arrolar características que são atribuídas à tradução, ao tradutor e à sua tarefa. Por exemplo: "o tradutor precisa ter conhecimentos profundos - lexicais, morfológicos, semânticos, pragmáticos e culturais" (Borges, 1997) - nas duas línguas em confronto, ou seja, ter uma ótima - para não dizer excelente - proficiência lingüística; conhecer o tema do texto a ser traduzido (proficiência temática); saber interpretar e tirar do texto todas as informações que possam guiar suas decisões; ter conhecimento das estraté- 
gias ou técnicas de transferência necessárias e adequadas e saber colocá-las em prática, tudo isso para produzir um texto na lingua-meta (também denominada lingua de chegada) com base em outro texto produzido em outra língua (Nord, 1997: 101-124); ser capaz de produzir no leitor o desejo de ler e despertar nele a mesma admiração pelo texto traduzido do que aquela suscitada pelo texto original.

Outro teórico da tradução (Stolze, 1997: 144-155), na defesa do tradutor competente, a serviço do que ele denomina 'atividade de comunicação', enumera os erros a serem evitados na prática, erros que denunciam a falta de uma das competências básicas do tradutor e que ele deve conscientemente evitar. Dentre eles, citem-se os seguintes: infringir a ortografia, a gramática e a sintaxe na língua-alvo, provavelmente por interferência lingüística (competência lingüística); evitar sentidos errôneos como um desvio semântico do original, por ignorar ou não compreender uma palavra ou expressão; omitir partes importantes do texto (competência temática e lexical); deixar passagens incompreensíveis, com erros de coerência e idéias confusas (competência temática); não saber adequar a expressão ao leitor (competência pragmática). Mais adiante, Stolze propõe essas mesmas competências como categorias tradutórias da avaliação de qualidade. Ora, aqui se coloca uma primeira questão: quem avalia - o leitor ou outro especialista? Se for o leitor, ele não terá o original em mãos para confrontar e se dar conta dessas falhas. No segundo caso, configura-se uma relação de poder, já que apenas um especialista com reconhecido saber poderá aferir tais erros.

Sabemos que, para vários especialistas e, também, para os leitores que normalmente buscam na obra traduzida não o tradutor, mas o autor do original, que o bom tradutor ou o tradutor ideal é aquele que desaparece para dar lugar ao autor; é aquele que consegue ser tão fiel ao autor e, portanto, à obra que se torna transparente: apenas um instrumento que se retira tão logo a obra se completa. E, para isso, logicamente, todas as competências acima elencadas e outras mais se fazem necessárias.

Mas, parece também lógico que ser assim competente supõe a "posse" consciente de um conhecimento totalizante ou 
completo de duas línguas que, por sua vez, também se apresentam como completas; melhor dizendo, supõe um sujeito centrado, racional, capaz de controlar-se a si próprio e a suas palavras, de modo a que estas nada carreguem dele ou, como diria Derrida (1972: 06), capaz de "dominar o objeto sem nele tocar". Esse sujeito, tanto quanto a língua, poderia ser definido como ser totalizante, capaz de reunir em si um saber idealmente completo, de que decorre o seu poder (Foucault, 1979), ou melhor, a sua confiabilidade, a sua competência. O tradutor é, assim, para esses especialistas (com conseqüências importantes para a prática da tradução) um sujeito consciente, melhor dizendo, um super-sujeito, cuja racionalidade deve idealmente constituir sua subjetividade (cf. Descartes).

Parece óbvio, portanto, que arrolar características para definir o tradutor proficiente ou criar categorias para classificar uns e outros significa assumir uma visão essencialista da tradução, da linguagem. Uma visão que fixaria, ainda que ilusoriamente e por um dado momento, uma identidade na qual o sujeito-tradutor poderia se reconhecer, já que certamente fazem parte do seu imaginário e, possivelmente, das representações simbólicas (inconscientes), valores que constituem a ética do tradutor. Sabe-se, entretanto, como já foi dito, que a identidade é ilusória, constituída que é de idealizações falaciosas - confortáveis, certamente, mas nem por isso menos mentirosas -, responsáveis pela construção de estereótipos generalizantes. Afinal, todo tradutor sabe da dificuldade de encontrar palavras que traduzam o sentido que ele crê ter sido conferido ao texto ou ao vocábulo pelo autor; todo tradutor sabe da dificuldade de dizer na sua cultura a cultura do outro que atravessa a linguagem do texto de partida.

2) O outro procedimento dos teóricos lidos nas revistas analisadas consiste em olhar o tradutor como um sujeito que sofre a instabilidade do momento histórico-social em que vive e que se faz presente, ainda que não de modo consciente, no texto que traduz. Isso significa adotar uma outra postura teórica, que desconfia da existência de uma essência definidora do sujeito como uno, completo, centrado, racional, capaz de controlar os efeitos 
de seu dizer e, portanto, de garantir os significados que produz, controlando também a sua consciência (Arrojo, 1992).

O sujeito postulado por essa visão se define - ainda que não explicitamente pelos autores dos textos analisados - como cindido, heterogêneo, inconsciente, constituído de fragmentos de outros discursos e de outros sujeitos, que o tornam instável, inefável, incapaz de controlar os efeitos de sentido de seu dizer e de encontrar a verdade. Assim, a linguagem não pode ser concebida como transparente, mas constitutiva do sujeito (sujeito da linguagem, segundo Lacan, 1966), opaca, lugar do equívoco e, portanto, lugar da cultura e da ideologia, o que anularia a possibilidade de vislumbrar a tradução como veículo, transporte de uma língua para outra. Nessa medida, somos levados a afirmar a identidade do tradutor - como, aliás, de qualquer sujeito como passageira, instável, sempre em movimento, em constante mutação e, principalmente, híbrida, constituída de fragmentos em conflito e em contradição, fragmentos da visão anterior, ideal e idealizada, e fragmentos da subjetividade em transformação, num mundo globalizado.

Neste caso, as imagens capturadas no discurso sobre a tradução falam de momentos, de perspectivas teóricas, provenientes de identificações, na maioria das vezes, inconscientes da parte do tradutor, na sua tarefa de interpretação, que carrega, sempre e inevitavelmente, traços do contexto histórico-social em que se insere o tradutor (e, portanto, a tradução resultante), traços de sua cultura (e, portanto, de sua subjetividade). Assim, questiona-se a fidelidade do tradutor ao texto de partida e/ou ao autor e imprime-se ao tradutor a tarefa de autor, porque, ao traduzir, modifica, sempre e inevitavelmente, o texto que interpreta, produzindo novos significados (Venuti, 1992). Dentre esses textos, destacam-se aqueles produzidos, principalmente, na Unicamp (Esteves, 1992; Rodrigues, 1992, Lages, 1992), a partir dos trabalhos desenvolvidos por Rosemary Arrojo. De forma sintética, poderíamos dizer, juntamente com a autora e teórica, que eles perscrutam

a voz e a marca do tradutor no trabalho que realiza a partir de vários ângulos e [...] examinam algumas conseqüên- 
cias do reconhecimento dessa voz e dessa marca, sempre sob a inspiração daquela sacudida providencial que a desconstrução tem [...] permitido aplicar aos preconceitos milenares que têm envolvido a atividade tradutória. (Arrojo, 1992: 08)

\section{O que dizem os tradutores ou especialistas da prática da tradução...}

A análise efetuada permitiu observar que as principais visões de tradução que perpassam os textos dos especialistas-tradutores analisados são atravessadas por diferentes vozes de teóricos da tradução. Essas visões gravitam em torno de três eixos principais que ora se distinguem nitidamente, ora se intersecionam, ora se mesclam, ora, ainda, se embaralham e se confundem. O primeiro eixo se encontra centrado no autor ou no texto; o segundo, no leitor e o terceiro, no tradutor.

Aquele cujo foco recai sobre o autor do texto-base exige do tradutor um alto grau de fidelidade às intenções do autor, às idéias que ele defende, cujas marcas se encontram impressas nas palavras, nos argumentos usados. Como conseqüência, é possivel afirmar que o foco está no texto, cujo sentido único, impresso nos signos lingüísticos que o constituem, deve ser garantido e respeitado na tradução. Esta, neste caso, "é vista como equivalência, mimese, reprodução" (Nóbrega, 1992: 83), ou "como reprodução de um original" (Staut, 1994: 35). ${ }^{2}$ E o tradutor, por sua vez, é visto como meio, instrumento onde ocorre a passagem de uma língua a outra. Como é privilegiado o aspecto lingüístico, os textos que adotam esta postura recorrem a contribuições que vão da terminologia (hoje informatizada), lexicografia, à pragmática, semântica e lingüística do discurso ou do texto.

2 Embora o texto de Staut se concentre na recepção da obra traduzida (no caso, Machado de Assis, traduzido para o francês), em vários momentos, é possível perceber que há uma preocupação forte com a "preservação" de "procedimentos estilísticos que caracterizam e individualizam sua narrativa" (p. 42). 
Vale a pena trazer aqui parte da conclusão do texto de Staut (op. cit.: 42), onde fica clara a preocupação com uma forte fidelidade ao texto e ao autor:

(...) ao se propor a exercer o papel de intermediário, [o tradutor] necessita dos quatro estômagos no cérebro para perceber, reconhecer e compreender criticamente os procedimentos estilísticos do original para, então, buscar reproduzi-los em outro idioma, veiculando, sempre que possivel, uma mensagem homóloga e isomorfa da primitiva, apta a provocar também no leitor estrangeiro efeitos semelhantes aos provocados pelo texto original.

Atente-se para a definição de tradutor como intermediário que precisa "reproduzir em outro idioma" uma dada obra, cuidando para que passe ao leitor da obra traduzida "uma mensagem homóloga e isomorfa da primitiva". Fica claro, parece-nos, que se prega, aqui, fidelidade ao autor ou ao texto, de modo a também ser fiel aos "efeitos" que a obra original (ou primitiva) provoca no leitor da lingua de partida. Ora, como saber que efeitos uma obra provoca no leitor sem generalizar aqueles que certamente se produzem nele, especialista, no momento da leitura? Como ser fiel ao autor e aos procedimentos estilísticos a não ser que se acredite na transparência das línguas, na possibilidade de transposição ou transferência lexical, morfológica, sintática, estilística e cultural entre duas ou mais línguas? Voltaremos a essas considerações mais adiante.

Ao lado dessa visão que se atém aos elementos lingüísticos, hoje talvez menos difundida do que há algumas décadas atrás, mas que são freqüentemente trazidas, de modo mais ou menos camuflado por alguns autores dos textos analisados e por outros, como estratégia argumentativa em favor de sua postura teórica, ganha(m) força aquela(s) que focaliza(m) especificamente a situação de leitura na tarefa de passar um texto para uma outra língua ou na tarefa de estudar os efeitos produzidos pelo texto traduzido sobre o leitor (Rodrigues, 1985). No primeiro caso, o tradutor precisa ficar atento ao tipo de texto, à situação de leitura, como se fosse possível imaginar quando, onde e 
quem irá ler o texto traduzido. No caso seguinte, o tradutor precisa ter consciência dos efeitos que o uso de "marcação de pensamentos e falas" pode provocar no leitor, "tornando o texto nebuloso", por exemplo (Rodrigues, op. cit.: 105). Fazem parte desta visão os tradutores (pautados em teóricos, evidentemente) que definem (ou definiam) a tradução como um ato de fidelidade semântica e pragmática; isto é, fidelidade ou lealdade ao sentido que o tradutor, que é também um leitor, imprimiu ao texto, e fidelidade (cf. 1t. fides = fé) à(s) possivel(eis) futura(s) situação(ões) de leitura, buscando controlar os efeitos de sentido que o texto resultante da tradução poderá provocar nos supostos futuros leitores; tal controle - desejado, embora impossivel de ser atingido - se dá através da busca esmerada das palavras corretas, atitude sustentada na concepção de linguagem transparente. É o que parece sugerir a conclusão do texto já citado (o tradutor deve ser também analista da obra traduzida), embora, nele, já se perceba uma forte tendência a considerar a multiplicidade de sentidos que todo texto carrega em seu bojo:

O tradutor é um dos fruidores da obra, mas como transmutador deve posicionar-se também como seu analista, nunca como seu único intérprete. A obra transmutada também tem que ser passivel de mil interpretações diferentes (Rodrigues, op. cit: 126)

Ainda nesta visão, o leitor pode ser substituído pelo mercado editorial "para o qual a tradução é dirigida" (Milton, 1994: 23); um mercado que pode exigir, além ou ao lado das "traduções criteriosas", um trabalho de condensação; esta pode ser, segundo o autor, encoberta ou evidente (textos adaptados). $\mathrm{O}$ texto em questão analisa os critérios de condensação utilizados pelos tradutores e as normas exigidas pelas editoras que, mais do que o leitor (virtual), exercem "um controle muito grande sobre a tradução", ao lado da conjuntura politica da época (op. cit.: 31).

Cabe ressaltar que, tanto na primeira quanto na segunda visões, o tradutor é concebido como um sujeito consciente, que desempenha o papel de intermediário, verdadeiro instrumento 
que serve de veículo, no primeiro caso, entre duas línguas e, no outro, entre o autor/texto e o leitor.

Como é possivel perceber, embora isso ocorra de modos diferentes, em ambos os casos, mesmo naquele em que o leitor constitui o foco, o texto, tomado como unidade de sentido, é o lugar para onde convergem todas as preocupações. Traduzir, então, é assumir o lugar do autor, o que pode ser sintetizado como sendo o desejo de autoria, de ser tão bom quanto o autor, de se ver no lugar daquele que se deseja, com cujos traços o sujeito-tradutor se identifica, mas que jamais atingirá. Gesto de soberba, como aquele que levou à construção da Torre de Babel e, ao mesmo tempo, gesto de humildade, de submissão e até de sentimento de inferioridade, que explicita a consciência de jamais poder vir a ser o autor. Isso, aliás, resulta de uma atitude de mitificação do autor por parte do tradutor que se curva diante dele, sobretudo quando se trata de um nome (re)conhecido, a ponto de almejar uma fidelidade ímpar, o que o leva a lutar com todas as suas forças contra qualquer gesto de interpretação a qual, por alguma razão, venha a corromper as idéias ou as palavras do mestre. O segmento seguinte, extraído da apresentação do romance On the road, de Jack Kerouac, traduzido por Eduardo Bueno e Antonio Bivar e trazido por Nóbrega (1992: 83), um dos artigos que serviram de corpus para esta análise, é um bom exemplo desse desejo de fidelidade:

Então, fui co-traduzindo assim: sendo mais amadurecido, contornei o estilo para que o resultado fosse fiel à cor local do original: o clássico que já é. Santo Jack Kerouac do céu nos sorria aprovando a dupla perfeita para a tarefa.

Observe-se o desejo dos tradutores de serem fiéis "à cor local do original", e de serem fiéis ao autor que "do céu nos sorria", metáfora que permite considerar o lugar de superioridade e, por que não dizer, o lugar sagrado que ocupa o autor do textobase, explicitado, ainda, pela denominação de "Santo". Ao lado dessa atitude de contemplação, está o desejo de perfeição e de completude dos tradutores que, como eles mesmos afirmam, constituem "a dupla perfeita para a tarefa". Arrogância, falta de 
modéstia? Talvez nem uma coisa nem outra: apenas a expressão de um desejo que muitos não ousam explicitar, mas que motiva a permanência da atividade tão pouco reconhecida economicamente naquele que precisa (ou assim acredita), para então se tornar autor, desaparecer, escondendo-se sob o manto protetor do escritor admirado e legitimado.

Noutros casos, os dois eixos se confundem, de forma mais acentuada, nos textos analisados, movidos por uma preocupação dos tradutores (especialistas), ao mesmo tempo, de fidelidade e de defesa do(s) sentido(s) possivel(eis) do original. Neste caso, o tradutor se ergue em arauto do autor, disposto a ajudar o leitor na tarefa de compreender o texto consagrado, como é possível perceber no seguinte excerto extraído do prefácio da tradução em francês das Obras Completas de Platão:

... tenho consciência de ter feito um esforço sincero para não trair meu autor e para torná-lo acessivel a todos aqueles que se interessam pela idéias e gostam da nobreza do espírito. ${ }^{3}$

Vale observar o uso do pronome "meu (autor)" que aponta para uma apropriação total do outro, no final do prefácio, sinal de identificação entre tradutor e autor, marca da admiração - e do desejo - do primeiro pelo segundo.

No final dessa mesma apresentação, faz-se ouvir fortemente o desejo de controle do(s) efeito(s) de sentido(s), que nada mais é do que conseqüência do desejo de autoria (de certa forma recalcado, frustrado, acobertado....), de assumir o lugar do outro (autor renomado) e de, como autor, defender o(s) sentido(s) que acredita poder controlar, defendendo também o texto do(s) efeito(s) de sentido indesejável(eis), embora pareça consciente dessa dificuldade, para não dizer dessa impossibilidade:

3 Traduzido do francês: “...j'ai conscience d'avoir fait un effort sincère pour ne pas trahir mon auteur et pour le rendre accessible à ceux qui s'intéressent aux idées et qui aiment la noblesse de l'esprit." (Robin, 1950: xix) 
Sempre que houve algum desacordo relativamente importante sobre a leitura ou a interpretação do texto, eu assinalei, dizendo que sentido dariam tal leitura ou tal outra interpretação. Por vezes também, para não entrar no detalhe de uma discussão sem saída, limitei-me a mencionar a incerteza do texto ou do sentido. ${ }^{4}$

A necessidade do tradutor de explicitar suas dificuldades, as escolhas realizadas e os procedimentos adotados constitui uma confissão da não-coincidência enunciativa (Authier-Revuz, 1998); isto é, de que o enunciador-tradutor não controla os efeitos de sentido da linguagem, sempre porosa, aberta a múltiplas interpretações: se a linguagem fosse transparente, então por que tentar cercear as interpretações ("dizendo que sentido dariam tal leitura ou tal interpretação")? Se assim não fosse, por que acenar para "uma discussão sem saída" ou "mencionar a incerteza do texto ou do sentido"? Percebe-se aí certa angústia-que, aliás, constitui a todo tradutor - e que provém, quero crer, da certeza, inconsciente, da impossibilidade e da necessidade de traduzir de que fala Derrida (1987); da impossibilidade de controlar os sentidos, as interpretações (efeito também da certeza, sempre inconsciente); da certeza de que a linguagem é o lugar do equívoco, da não coincidência entre o dizer e o sentido que nele se quer, conscientemente, imprimir; da certeza, enfim, da inefabilidade e da impossibilidade do controle de si, do outro, de todos os sentidos disseminados no texto e no sujeito... Assim, na busca de estancar e, assim, garantir o(s) sentido(s) desejado(s), abre-se a porta por onde escapa o inefável, o impossivel, o descontrole, a opacidade da linguagem.

Dos textos analisados, que abordam a prática tradutória, pode-se depreender, ainda, como já foi assinalado, um terceiro

4 Traduzido do francês: "Partout où il y a désaccord de quelque importance sur la lecture ou l'interprétation du texte, je l'ai signalé, en disant quel sens donneraient telle autre lecture et telle autre interprétation. Parfois aussi pour ne pas entrer dans le détail d'une discussion sans issue, je me suis borné à mentionner l'incertitude du texte ou du sens." (Robin, 1950: xix) 
eixo, menos enfatizado do que os demais: aquele cujo foco recai sobre o tradutor, defendendo a sua visibilidade, opacificada ou esquecida nos dois eixos anteriores. Nessa perspectiva teórica, a tradução, tal como constatamos nos textos teóricos, é vista como interpretação, extrapolando, em alguns poucos casos, a tradução entre línguas, à maneira de Derrida (1987). Traduzir é, então, transformar, produzir um texto (Martins \& Frota, 1997; Brezolin, 1997) que não será nem totalmente novo/diferente, porque toma como ponto de partida o texto-base, nem totalmente o mesmo, porque toda interpretação gera inevitavelmente outro texto e todo texto é tecido, é textura que, por se encontrar dissimulada, escondida,

pode levar séculos para desfazer seu pano. O pano envolvendo o pano. Séculos para desfazer o pano. Reconstituindo-o também, como um organismo. Regenerando indefinidamente seu próprio tecido por detrás do rastro cortante, a decisão de cada leitura. Reservando sempre uma surpresa à anatomia ou à fisiologia de uma crítica que acreditaria dominar o jogo, vigiar de uma só vez todos os fios, iludindo-se, também, ao querer olhar o texto sem nele tocar, sem pôr as mãos no "objeto", sem se arriscar a lhe acrescentar algum novo fio, única chance de entrar no jogo tomando-o entre as mãos. Acrescentar não é aqui senão dar a ler. (Derrida, 1972: 07)

Ler, interpretar, traduzir consiste sempre, nessa visão, em acrescentar, acrescentando-se, em juntar, (a)juntando(-se). Nesse sentido, é possivel afirmar que tradução é sempre escritura e inscritura de si e do outro os quais, afinal, se constituem no mesmo e no diferente.

Se os textos teóricos, apesar da tendência a uma coerência teórica, já deixam perceber certa mistura entre os eixos apresentados, os textos escritos por práticos da tradução, ou por especialistas que teorizam sobre a prática, se apresentam muito mais controversos e menos racionalmente coerentes. Percebe-se certo 'ecletismo' teórico, ainda que, por vezes, esteja explicitado no artigo um determinado posicionamento. Talvez isso se expli- 
que pelo fato de se basearem em experiências várias que os levaram a se posicionar com relação às dificuldades lingüísticas de ordem lexical, morfológica e sintática; posicionar-se com relação ao tema e, ainda por cima, com relação aos fatores de ordem pragmática, que alguns autores consideram externos ao texto: emissor, destinatário, intenção, canal, data, local, função, sobretudo função do texto traduzido ao qual o tradutor deve lealdade mais do que fidelidade (Hörster, 1977: 47-68).

Para sintetizar, poderíamos dizer que os textos sobre prática de tradução dão testemunho do desejo de completude, de conhecimento totalizante, na ânsia pela perfeição, pela fidelidade ou lealdade que, ora mais, ora menos explicitamente, nos define enquanto tradutores de textos que admiramos e dos quais gostariamos de ser autores - embora, de certa forma, já o sejamos. Talvez possamos dizer das obras que traduzimos, especialmente as obras literárias - quando podemos escolher, é claro - o mesmo que Costa Pinto (2003: 62) disse a respeito das obras sobre as quais escreve e analisa: “(...) a escolha dos livros sobre os quais escrevo a seguir também obedece a um critério mais simples: são os livros que gostaria de ter escrito".

Mesmo quando se trata de textos não literários, a contingência da tarefa - objetivos da empresa, tempo reduzido, tipo de texto - leva o tradutor a se sentir mais ou menos frustrado, porque nem sempre, ou quase nunca, pode realizar o trabalho que desejaria - trabalho de pesquisa, de busca pelos termos que reproduzem, ainda que ilusoriamente, o sentido do original.

\section{Alguns alinhavos apenas...}

Para concluir, poderíamos dizer que o sujeito-tradutor, herdeiro que é de diferentes concepções teóricas que assimila de forma mais ou menos consciente, assumindo o discurso do outro - teórico ou especialista da tradução, cuja autoridade ele legitima e que, por isso mesmo internaliza - se encontra, então, numa região de conflitos entre o desejo de fidelidade e de reverência ao autor do texto-base e o desejo de ser o lugar da origem, de ser completo, que se traduz na ânsia de criatividade e de 
autoria. Ao mesmo tempo em que defende a tradução como criação, o tradutor ou o autor do texto traduzido afirma se ater a cada palavra na preocupação com o sentido do texto: deseja-se fiel, mas depara-se com a infidelidade; pretende-se conhecedor profundo das línguas em questão, mas enfrenta situações em que lhe é impossibilitada a expressão, em que os sentidos e as palavras lhe escapam e isso nas duas linguas (ainda que uma delas seja o que se denomina sua lingua materna); imagina controlar os sentidos, de modo a aproximar o mais possivel daqueles que supõe estarem impressos no texto de partida, mas vê-se na contingência de enfrentar críticas à sua tradução; deseja, enfim, desaparecer, tornar-se invisivel, mas percebe que está sempre presente, nas notas de rodapé (que reduz ao mínimo em obediência às regras editoriais), nas escolhas que torna a sua tradução singular - sempre semelhante a outras, mas ao mesmo tempo sempre diferente.

$\mathrm{Na}$ esteira do que está sendo colocado, percebe-se, tanto nos teóricos quanto nos tradutores, o desejo ao apagamento dos aspectos culturais próprios da atividade tradutória e, portanto, ao apagamento das diferenças, para privilegiar a cultura do outro, as formas lingüísticas, através do processo de normalização, de classificação. Lugar de instabilidade e de conflitos, ser tradutor parece significar um saber operar com sentidos que se cruzam, provenientes de várias regiões de discurso, o que nos leva a afirmar que, em vez de fixidez, o que existe é contingência; lugar onde o que parece determinado é, na verdade, fluido e inseguro, sem pontos de fechamento e estabilidade.

$\mathrm{O}$ tradutor se encontra, pois, entre a ânsia de fidelidade e a impossibilidade de ser fiel; entre a busca das intenções do autor e a impossibilidade desse encontro; entre o consciente e o inconsciente; entre a necessidade e a impossibilidade da tradução; entre a reprodução e a criação; entre a ilusão do controle de si, do seu dizer, dos efeitos de sentido de seu dizer e o inefável. Enfim, o tradutor se encontra entre o desejo do conforto da determinação e a contingência desconfortável da indeterminação, terreno movediço onde os sentidos deslizam, escapam, adiando ad infinitum o tão desejado porto seguro e o conforto da totalização; entre a necessidade da invisibilidade e o desejo de um reco- 
nhecimento social (e econômico); entre a língua do outro e a língua dita materna, já que o tradutor também poderia dizer juntamente com Derrida (1996) "só tenho uma língua, ela não me pertence", ou com Lacan: "sou estrangeiro em minha própria casa", ou ainda com Kristeva (1988): "o estranho habita em nós", ou com Rimbaud: "Eu é um outro" - e é na e pela identificação com o outro que todo sujeito define sua identidade que, tal como a linguagem, desliza, escapa, derrapa...

\section{Referências Bibliográficas:}

ARAÚJO, L. A. de (1992) O tradutor e o computador: possibilidades de uma interface. Trabalhos em Lingüística Aplicada, 19 (jan./jun.), Campinas: IEL-DLA, Unicamp.

ARROJO, R. (1992) A tradução passada a limpo e a visibilidade do tradutor. Trabalhos em Lingüistica Aplicada, 19 (jan./jun.), Campinas: IEL-DLA, Unicamp.

. (1992a) Apresentação. Trabalhos em Lingüística Aplicada, 19 (jan./ jun.), pp. 5-8, Campinas: IEL-DLA, Unicamp.

AUTHIER-REVUZ, J. (1998) Palavras incertas. Trad. Claudia Pfeiffer \& alii. Campinas: Editora da Unicamp.

BACKES, C, (2000) O que é ser brasileiro? São Paulo: Escuta.

BAUMAN, Z. (2001) Modernidade Líquida. Trad.: Plínio Dentzien. Rio de Janeiro: Jorge Zahar.

BERRY, N. (1991) O Sentimento de Identidade. Trad. Maria José R. F. Coracini. São Paulo: Escuta.

BORGES, L. C. (1997) Donne - soneto sagrado XIV. Cadernos de Literatura em Tradução, 1. São Paulo: Humanitas, USP.

BREZOLIN, A. (1997) Humor: Sim. É possivel traduzi-lo e ensinar a traduzi-lo. TradTerm, 4 (1), pp. 15-30, São Paulo: Humanitas, USP. COSTA PINTO, M. da (2003) Introdução. In B. Ajzenberg e outros: Tha Deserta. São Paulo: Publifolha, pp. 61-95.

DERRIDA, J. (1972) A Farmácia de Platão. Trad.: Rogério da Costa. São Paulo: Iluminuras. 1991.

. (1987) Tours de Babel. In: Jacques Derrida: Psyché. Paris: Galilée. Trad.: Junia Barreto. Torres de Babel. Belo Horizonte: Editora da UFMG, 2002. 
(1996) Le monolinguisme de l'autre. Paris: Galilée.

ESTEVES, L. (1992) As várias faces e fases de um original shakespereano. Trabalhos em Lingüística Aplicada, 19 (jan./jun.), Campinas: IEL-DLA, Unicamp.

FOUCAULT, M. (1979) Microfisica do Poder. Org. e trad.: Roberto Machado. Rio de Janeiro: Graal, $11^{\text {a }}$ edição.

HÖRSTER, M. A. F. (1997) A Cadeira de Tradução Alemão-Português I (linguagem comum). TradTerm, 4 (1): 47-68, São Paulo: Humanitas, USP.

KRISTEVA, J. (1988) Etrangers à nous-mêmes. Paris: Editions Gallimard.

LACAN, J. (1966) Ecrits. Paris: Editions du Seuil.

LAGES, S. K. (1992) O tradutor e a melancolia. Trabalhos em Lingüística Aplicada, 19 (jan./jun.), Campinas: IEL-DLA, Unicamp.

LERAY, C. (2003) A língua como vetor identitário: o caso do gaulês na Bretanha. In: Maria José Coracini (org.) Identidade e discurso: (des)construindo identidades. Campinas, Chapecó: Editora da Unicamp, Argos.

MARTINS, M. A. P. \& FROTA, M. P. (1997) Avaliação de tradução: a vez e a voz do aprendiz. TradTerm, 4 (1), pp. 69-84, São Paulo: Humanitas, USP.

MELMAN, C. (2002) L'homme sans gravité. Paris: Editions Denoël.

MERCER, K. (1990) Welcome to the jungle. In: RUTHERFORD, J. (org.) Identity: community, culture, difference. Londres: Lawrence and Wishart.

MILTON, J. (1994) A tradução de romances "clássicos" do inglês para o português no Brasil. Trabalhos em Lingüística Aplicada, 24 (Jul/dez.), pp. 19-33. Campinas: IEL-DLA, Unicamp.

NÓBREGA, T. M. (1992) A tradução intercultural de "On the road": contra a diferença. Trabalhos de Lingüistica Aplicada, 19 (jan/jun.), pp. 83-89, Campinas: IEL-DLA, Unicamp.

NORD, C. (1997) El texto buscado - los textos auxiliares en la enseñanza de traducción. TradTerm, 4 (1): 102-124, São Paulo: Humanitas, USP.

OTTONI, P. (1997) O papel da lingüística e a relação teoria e prática no ensino da tradução. TradTerm, 4 (1), pp. 125-139, São Paulo: Humanitas, USP.

ROBIN, L. (1950) Preface. In Platon: Oeuvres Complètes. Trad.: Léon ROBIN. Paris:Les Belles Lettres. 
RODRIGUES, C. C. (1985) Uma leitura de Absalom, Absalom! De Faulkner e de sua tradução. Tradução e Comunicação, 7 (dez.), pp. 95-130, São Paulo: Álamo e Faculdade Ibero-Americana. . (1992) O sujeito no texto: o teórico, o tradutor e o leitor. Trabalhos em Lingüistica Aplicada, 19 (jan./jun.), pp.75-81. Campinas: IEL-DLA, Unicamp.

STAUT, L. M. (1994) Traduções francesas na obra machadiana. Trabalhos em Lingüística Aplicada, 24 (jul./dez.), pp. 35-43. Campinas: IEL-DLA, Unicamp.

STOLZE, R. (1997) Indicadores de qualidade para a avaliação de traduções no âmbito da didática. TradTerm, 4 (1): 157-173, São Paulo: Humanitas, USP.

VENUTI, L. (1992) Simpatico. Trabalhos em Lingüística Aplicada, 19 (jan./jun.), pp. 21-39. Campinas: IEL-DLA, Unicamp. 